\title{
Infarct vessel status after intravenous tissue plasminogen activator and acute coronary angioplasty: Prediction of clinical outcome
}

\begin{abstract}
To determine the risk of arterial reocclusion or recurrent ischemia after acute intervention in myocardial infarction, we analyzed the results of coronary arteriography performed acutely and at 1 week in 50 consecutive patients who received acute intervention. Successful recanalization of the infarct vessel was achieved in $46(92 \%)$ patients after therapy with intravenous tissue plasminogen activator, percutaneous coronary angioplasty, or both. Follow-up angiography in 44 showed early reocclusion in 10 patients $(23 \%)$. Intermittent patency during acute arteriography was always associated with reocclusion; suboptimal (Thrombolysis in Myocardial Infarction [TIMI] class 2) flow was associated with a $50 \%$ rate of reocclusion. Although residual stenosis of $>50 \%$ alone was not predictive of rethrombosis, $90 \%$ of all reocclusions were associated with either stenosis $>\mathbf{5 0} \%$, TIMI 2 flow, or intermittent patency. Absence of these angiographic risk factors predicted a $95 \%$ patency rate at follow-up. In-hospital cardiac complications occurred in 17 of 23 (74\%) patients with residual stenosis of $>50 \%$ (death in four, ischemia in 13), and late revascularization was required in $\mathbf{5 3} \%$ of survivors. Only $15 \%$ of the group with $<50 \%$ stenosis had an in-hospital ischemic event $(p<0.001)$. Thus, after acute intervention, an infarct vessel with intermittent patency or suboptimal flow is associated with a high rate of reocclusion. Residual stenosis $\geq \mathbf{5 0} \%$ appears to predict a high incidence of negative in-hospital clinical outcomes and the need for subsequent revascularization. (AM HEART J 1988;115:1.)
\end{abstract}

Cindy L. Grines, M.D., Eric J. Topol, M.D., Eric R. Bates, M.D., Jack E. Juni, M.D., Joseph A. Walton, Jr., M.D., and William W. O'Neill, M.D. Ann Arbor, Mich.

Recently, results of several large randomized trials have shown a reduction in mortality in acute myocardial infarction (MI) with the early use of thrombolytic agents. ${ }^{1.4}$ Despite the reduction in mortality observed with thrombolytic therapy, the incidence of reinfarction or recurrent ischemic events is increased. ${ }^{1,2,5}$ Acute angiographic studies have shown that after successful thrombolysis, there is a high-grade residual coronary stenosis in most patients. ${ }^{6}$ Emergent percutaneous transluminal coronary angioplasty (PTCA) has the potential to reduce infarct vessel stenosis and may prevent recurrent ischemia. ${ }^{7,8}$

With the likelihood of wide-scale use of intravenous thrombolysis, it will become increasingly

From the Division of Cardiology, Department of Internal Medicine, University of Michigan Medical Center.

Received for publication June 30, 1987; accepted Aug. 12, 1987.

Reprint requests! Eric J. Topol, M.D., Division of Cardiology, University of Michigan Medical Center, UH B1 F245, 1500 E. Medical Center Dr., Ann Arbor, MI 48109-0022. important to select those patients who need early definitive revascularization. The present study was undertaken to define whether there are arteriographic predictors of adverse clinical outcome and early reocclusion of infarct vessel.

\section{METHODS}

Study design. The study design has been described previously. ${ }^{9}$ Briefly, 50 consecutive patients with acute MI, who were initially seen within 6 hours of onset of symptoms were randomly assigned on a 3:1 basis to groups receiving either intravenous recombinant tissue plasminogen activator (t-PA), $1.25 \mathrm{mg} / \mathrm{kg}$ over 3 hours, or placebo.

Coronary angiography was performed at 60,90 , and 120 minutes after the infusion was started. The final infarct vessel patency determination was made at 120 minutes according to the Thrombolysis in Myocardial Infarction (TIMI) study classification ${ }^{10}$. Infarct vessels showing TIMI 2 or 3 flow patterns were considered to be patent. If residual stenosis $>50 \%$ was present in a patent vessel, these patients were randomly assigned to either emergent PTCA or no PTCA. Patients with significant disease of 


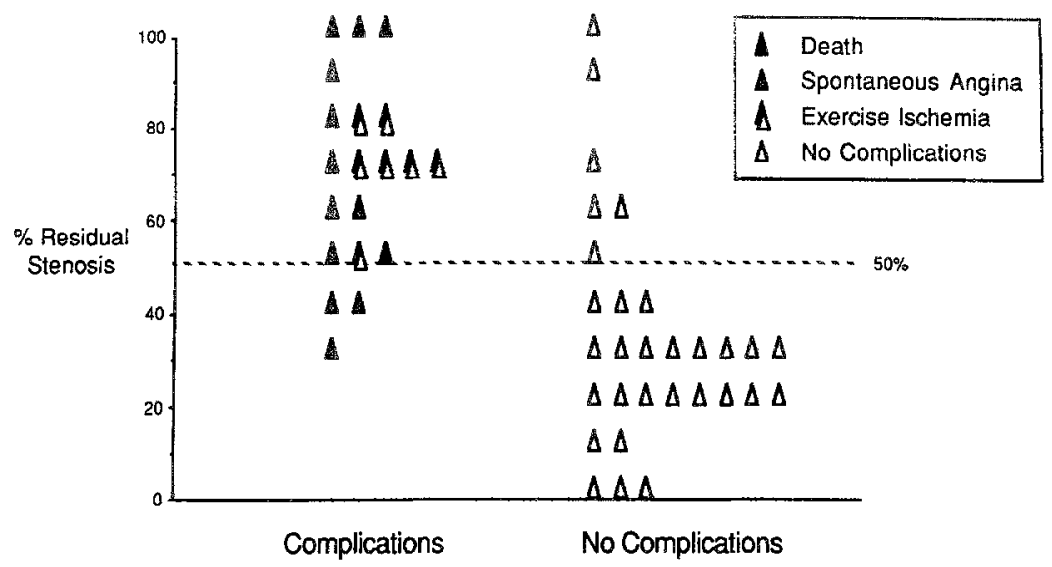

Fig. 1. Relationship between residual stenosis of infarct-related artery and subsequent in-hospital cardiac complications.

the left main artery were excluded from randomization. Those patients with an occluded artery defined as TIMI 0 or 1 underwent emergency angioplasty to attempt reperfusion.

All patients received 5000 units of heparin at the time of arterial access and an additional 5000 units just before coronary angioplasty if this procedure was performed during acute catheterization. After patients left the catheterization laboratory, they were given a continuous infusion of heparin 1000 units/hr, which was maintained until follow-up catheterization except for a few hours on the second hospital day when the arterial access sheath was removed. Patients were also treated with aspirin (325 $\mathrm{mg} /$ day), dipyridamole ( $75 \mathrm{mg}$ three times/day), and diltiazem (30 to $60 \mathrm{mg}$ four times/day).

Repeat cardiac catheterization was performed on day 7. Reocclusion of an infarct vessel was defined as a vessel that was patent (TIMI 2 or 3 flow) at the completion of acute intervention that was found to have TIMI 0 or 1 flow at follow-up angiography.

Angiographic analysis. Coronary arteriograms obtained during acule intervention were subsequently analyzed to visually assess the presence of thrombus and arterial dissection. Intraluminal thrombus was defined as a circular intraluminal filling defect or persistent contrast staining. Intimal dissection was diagnosed if a linear filling defect was present at the dilatation site. Intermittent coronary patency was defined as adequate (TIMI 2 to 3) flow that was spontaneously reduced to TIMI 0 to 1 on a later angiogram. Qualitative and quantitative coronary arteriographic analysis was performed by one observer blinded to patient identity, therapy, and effects of therapy.

Infarct vessel stenosis was determined by quantitative angiography with the use of an automated edge-detection computer algorith. ${ }^{11}$ To determine the percentage of the diameter of the stenosis, end-diastolic frames were chosen from the coronary arteriogram that demonstrated the most severe stenosis. These were digitized into $256 \times 256$ eight-bit matrices by means of a cine film projector equipped with a primary beam splitter coupled to a fixed-gain video camera and a video-to-digital converter. Images were stored in the memory of a digital radiographic computer (DPS 4100C, ADAC Laboratories, San Jose, Calif.) for subsequent processing. All values reported are quantitative angiographic results except when it was not possible to use the results of software analysis because of vessel overlap or inadequate film quality for digitization. The latter occurred in nine of the patients in the study and in these, the percentage of the diameter of the stenosis was determined by calipers.

Submaximal exercise testing with thallium-201 tomographic imaging. A submaximal stress test with thallium-201 tomographic imaging was performed before discharge (3 to 10 days after infarction). The patients" cardiac medications were not discontinued for the study. Upright treadmill exercise was performed in 3-minute uninterrupted stages with a constant speed of 2 miles/hr and a $3 \%$ grade increment for each stage. Complete 12-lead ECGs were obtained at rest and at the end of each stage of exercise. Thallium-201 chloride $(3 \mathrm{mCi})$ was injected intravenously at peak exercise and exercise was continued for one additional minute. Tomographic gamma camera imaging was then performed immediately with delayed views obtained 3 hours later. Exercise was terminated when one of the following conditions occurred: a target heart rate of $130 \mathrm{bpm}$, angina, marked ST segment depression, hypotension, serious ventricular arrhythmia, or exhaustion. The ECG was interpreted as positive for ischemia when the patient developed $2 \mathrm{~mm}$ or more of horizontal ST segment depression compared to the baseline tracing.

Scintigraphic imaging was performed by means of a wide-field-of-view gamma camera (GE 400AT) equipped with a general-purpose, parallel-hole collimator. Image data were acquired in 64 projections over a 180-degree arc beginning with the right anterior oblique and ending with the left posterior oblique position. Images were obtained in a $64 \times 64$ word mode image with 30,000 to 50,000 counts/image. Total acquisition time was approximately 
Table I. Baseline demographic and angiographic data*

\begin{tabular}{lcc}
\hline & \multicolumn{2}{c}{ Stenosis } \\
\cline { 2 - 3 } Variables & $>50 \%(n=23)$ & $<50 \%(n=27)$ \\
\hline No. of patients & 23 & 27 \\
Age & $53.3 \pm 11.9$ & $55.1 \pm 10.9$ \\
Male/female & $18 / 5$ & $21 / 6$ \\
Time to reperfusion & & \\
$\quad$ (hr) & $5.5 \pm 1.5$ & $5.4 \pm 1.1$ \\
Infarct artery & 13 & 12 \\
LAD & 0 & 4 \\
Cx & 10 & 11 \\
RCA & & 18 \\
No. of diseased vessels & 11 & 6 \\
1 & 8 & 3 \\
2 & 4 & \\
3 & &
\end{tabular}

Time to reperfusion $=$ Time from onset of chest pain w angiographically documented patency of infarct vessel; $\mathrm{LAD}=$ left anterior descending artery; $\mathrm{CX}=$ circumflex artery; $\mathrm{RCA}=$ right coronary artery.

*There were no significant $(p<0.05)$ differences between groups for the variables listed.

20 minutes. Tomographic reconstruction was then performed by means of a commercial convolution/back projection algorithm (GE STAR, General Electric, Milwaukee, Wisc.) withoul allenuation correction. The reconstrucled image data were reformatted to produce vertical, horizontal long-axis, and short-axis planes of section. Comparable images were obtained at the 3-hour imaging session.

An image defect was considered present if there was a discrete region of absent or decreased activity estimated visually. The defect was anatomically locallized as apical, anterior, septal, inferior, or lateral with the use of all sections. A defect present immediately after exercise and again at 3 hours' delay was considered to be indicative of infarction, whereas a defect present only immediately after exercise was considered to reflect ischemia. Either partial or complete resolution of a defect was considered evidence of reversible ischemia. If the reversible defect occurred adjacent to the zone of infarction, it was considered to represent periinfarct ischemia; if it occurred at a site removed from the zone of infarction, it was considered to represent distant ischemia.

Statistical evaluation. Data are presented as mean \pm 1 standard deviation unless otherwise stipulated. Student's $t$ and Fisher exact tests were used for statistical analysis where appropriate. Differences were considered significant at the $p<0.05$ level.

Clinical outcomes. Patients were monitored throughout their hospitalization for the following clinical events: (1) death; (2) postinfarction angina-recurrent chest pain at rest with accompanying ECG changes in the infarct territory; (3) reinfarction-prolonged chest discomfort with attendant enzymatic confirmation of creatine kinase-MB elevation; (4) exercise-induced ischemia-submaximal exercise testing before discharge clemonstrating reversible thallium-201 uptake in the region of the infarct
Table II. Clinical and angiographic outcomes

\begin{tabular}{|c|c|c|c|c|c|}
\hline & \multicolumn{4}{|c|}{ Stenosis } & \multirow[b]{2}{*}{$p$} \\
\hline & $>50 \%$ & $(n=23)$ & $<50 \%$ & $(n=27)$ & \\
\hline Death & & 4 & & 0 & 0.001 \\
\hline Post-MI angina & & 8 & & 4 & $<0.05$ \\
\hline Reinfarction & & 3 & & 1 & NS \\
\hline Periinfarct ischemia & & 7 & & 0 & $<0.001$ \\
\hline $\begin{array}{l}\text { In-hospital } \\
\text { complications }\end{array}$ & & 17 & & 4 & $<0.001$ \\
\hline $\begin{array}{l}\text { Need for delayed } \\
\text { PTCA/CABG }\end{array}$ & & 10 & & 1 & $<0.001$ \\
\hline
\end{tabular}

$\mathrm{CABG}=$ Coronary artery bypass graft; $\mathrm{NS}=$ not signiticant

zone. Reversible defects in the noninfarct zones were excluded. Subjects who required additional revascularization procedures before exercise testing were also excluded. Clinical events were coded by investigators who were blinded to the results of coronary angiographic analysis. Patients were considered to have reached a clinical end point if there was a recurrence of ischemia, at which time such patients were considered for revascularization with coronary angioplasty or coronary artery bypass surgery.

\section{RESULTS}

Angiographic results. Demographic and clinical data for the 50 patients have been previously reported. ${ }^{9}$ The results of infarct vessel patency are as follows: two of the 12 patients who received placebo (17\%) showed infarct vessel patency. Eleven of these patients underwent PTCA, which was successful in nine. Of the 38 patients receiving $\mathrm{t}-\mathrm{PA}, 71 \%$ had a patent infarct vessel at 90 minutes and by 120 minutes, 32 of 38 patients $(84 \%)$ had a patent vessel. It is noteworthy that five of these patients showed intermittent patency and occlusion during serial angiography. At six patients with failed t-PA thrombolysis underwent PTCA; flow was successfully reestablised in four. Of the 32 patients with successful t-PA thrombolysis, one underwent emergency bypass surgery because of left main coronary artery disease and three had $<50 \%$ residual stenosis of the infarct vessel. Of the 28 patients with high-grade stenoses after thrombolysis, 13 were randomly assigned to no PTCA and 15 were randomly assigned to immediate PTCA. All angioplasties in this group were successful with the mean stenosis decreasing from $80.8 \pm 8.2 \%$ to $32.5 \pm 15 \%$. With the addition of PTCA in patients with occluded vessels, overall patency was increased to $92 \%$.

Hospital course. Cardiac complications including death or spontaneous or provocable ischemia occurred in 21 patients. Fig. 1 shows the spectrum of severity of infarct vessel residual stenosis after acute 


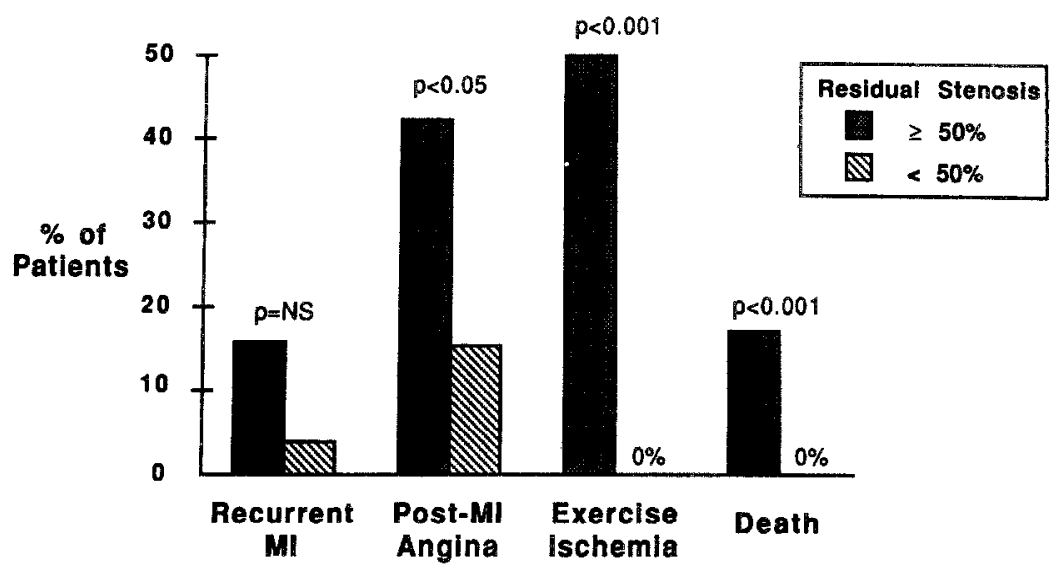

Fig. 2. Incidence of individual adverse cardiac events during hospitalization in two groups: $\geq 50 \%$ and $<50 \%$ residual stenosis.

intervention and its relationship to recurrent ischemic events. Of the 20 patients who had a cardiac complication, $17(85 \%)$ had infarct vessel residual stenosis $\geq 50 \%$; but 24 of $30(80 \%)$ of those with an uncomplicated hospital course had insignificant stenosis $(p<0.001)$. This predominance of adverse clinical events in patients with $>50 \%$ stenosis prompted a more detailed analysis of the angiographic subgroups.

High-grade residual stenosis, defined as more than $50 \%$ diameter narrowing, was present in 23 patients. This group comprised four patients with unsuccessful recanalization, four who underwent PTCA that was initially thought to be successful but who were later found to have $\geq 50 \%$ stenosis by quantitative arteriography, and 15 who did not undergo PTCA. Of the 27 patients with residual stenosis of less than $50 \%, 25$ underwent PTCA to reduce the stenosis; the remaining two patients had insignificant stenosis remaining after thrombolysis alone. There were no statistical differences in sex, age, time to reperfusion, location of infarct vessel, or presence of multivessel disease between the two groups (Table I).

Table II describes the incidence of in-hospital death or ischemia in the two groups: $\geq 50 \%$ or $<50 \%$ residual stenosis. There were four deaths in the trial. All four deaths occurred in patients with high-grade residual stenosis $(p<0.001)$; three of these patients had undergone unsuccessful reperfusion. The infarct-related artery was the right coronary in two and left anterior descending in two. Two of these patients had received placebo, recanalization did not occur spontaneously, and angioplasty was unsuccessful in achieving sustained patency. One patient failed $t$-PA thrombolysis and had only brief reperfusion after PTCA before the artery reoccluded in the laboratory. The other death was in a 73-year-old man who received t-PA (5.2 hours after the onset of chest pain) and emergent angioplasty (at 7.5 hours) but had a very extensive anterior infarction. Although PTCA was initially thought to be successful, subsequent analysis showed 55\% residual stenosis with TIMI 2 flow, thrombus, and arterial dissection. All four patients developed cardiogenic shock and recurrent ventricular tachycardia and fibrillation before death.

In addition to death, other adverse in-hospital clinical events were associated with high-grade residual stenosis (Fig. 1). Three of 19 (16\%) survivors with residual stenosis $>50 \%$ had in-hospital reinfarction but only 1 of 27 survivors (4\%) with minor residual obstruction $(p=0.15)$. Postinfarction angina occurred in 8 of the $19(42 \%)$ survivors with high-grade stenosis compared to only four $(15 \%)$ patients with $<50 \%$ residual stenosis $(p<0.05)$. Of the 14 patients with high-grade residual stenosis of the infarct artery who underwent exercise tomographic thallium scintigraphy, seven (50\%) showed evidence of periinfarct ischemia. Only one patient had ECG changes diagnostic of ischemia, the remaining ECGs could not be interpreted because of changes at baseline. Of the 23 patients with minor residual stenosis who underwent exercise testing, none had provocable ischemia $(p<0.001)$.

Cardiac complications, including postinfarction angina, recurrent infarction, exercise-induced ischemia, or death, were observed in $74 \%$ of patients with residual stenosis $>50 \%$ vs $15 \%$ of the group with $<50 \%$ stenosis $(p<0.001)$.

The need for delayed revascularization of the infarct artery was also determined for the two groups (Fig. 2). Fifty-three percent of survivors with 


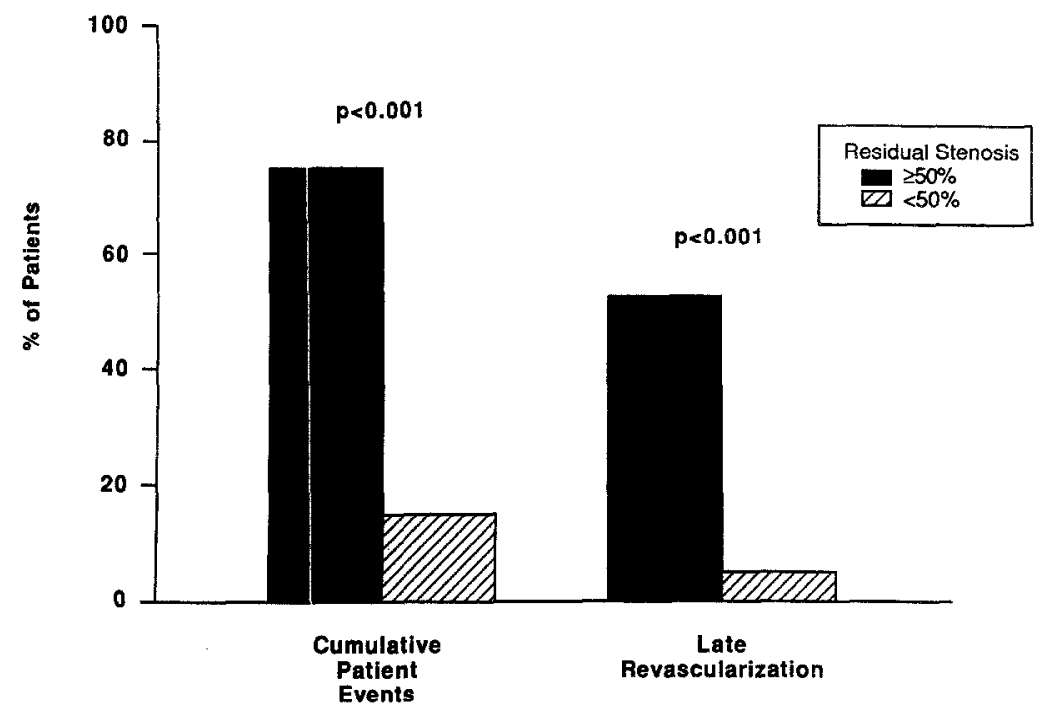

Fig. 3. Cumulative patient events ircluding death, reinfarction, and spontaneous or provocable ischemia for two groups: $\geq 50 \%$ and $<50 \%$. Late revascularization with bypass surgery or PTCA was performed for recurrent ischemia in $53 \%$ of survivors with $\geq 50 \%$ stenosis.

residual stenosis of the infarct artery $\geq 50 \%$ underwent late revascularization with either angioplasty or bypass surgery. Each patient received the additional intervention for spontaneous or exerciseinduced ischemia as previously defined. This $53 \%$ incidence of late revascularization for patients with high-grade residual lesions compares to only $4 \%$ in the group with $<50 \%$ stenosis $(p<0.001)$.

Reocclusion. Of the 46 patients with successful recanalization, 44 had follow-up coronary arteriography. In 10 patients the infarct artery was reoccluded at follow-up, which represents an incidence of $23 \%$.

Several angiographic features of the infarct artery at the completion of the acute intervention were evaluated to determine the relationship to early reocclusion. Time to reperfusion, location of infarct vessel, presence of thrombus or dissection, use of t-PA or placebo, use of PTCA, and successful vs unsuccessful t-PA thrombolysis were all considered and found not to be significantly different between patent and reoccluded groups. High-grade residual stenosis of the infarct artery was present in $50 \%$ of the vessels that reoccluded but not significantly different from those who remained patent $(41 \%)$. Only $26 \%$ of vessels with residual stenosis of $>50 \%$ were reoccluded at follow-up. TIMI 2 (suboptimal) flow was present in $30 \%$ of those vessels that reoccluded, and its presence was associated with a $50 \%$ reocclusion rate compared to a rate of only $18 \%$ in those vessels with TIMI 3 flow $(p=0.09)$. Intermittent patency was present in only five arteries and was associated with unsuccessful reperfu- sion in two. The three arteries with successful recanalization but intermittent patency during the acute procedure all were found to be reoccluded at follow-up catheterization (Fig. 3).

It is noteworthy that $90 \%$ of all reocclusions were associated with at least one of three angiographic features of infarct artery: high-grade residual stenosis, TIMI 2 flow, or intermittent patency during acute intervention. Absence of these risk factors predicted a $95 \%$ patency rate at follow-up.

In five patients, reocclusion was associated with chest pain and ECG changes. In three of these five patients, symptomatic reocclusion occurred within 24 hours after initial therapy. Reocclusion was silent in the remaining five patients. It should be noted that four of these five patients with silent reocclusion had well-developed collateral arteries to the infarct-related artery and one demonstrated periinfarct ischemia by exercise thallium.

\section{DISCUSSION}

Recurrent ischemia. Our results confirm the high incidence of reocclusion and recurrent ischemia after reperfusion therapy for acute MI. Use of intravenous t-PA, PTCA, or both may achieve high infarct vessel patency rates $(92 \%)$. Despite this high initial patency rate, a significant number of these patients (17 of 50) had recurrent ischemia or died during hospitalization. Eighty-five percent of patients with an in-hospital cardiac event had residual stenosis of the infarct artery $\geq 50 \%$. These patients had either not undergone PTCA or had a suboptimal result of angioplasty. 
Post-infarction angina occurred spontaneously in $42 \%$ of survivors with high-grade stenosis. Exerciseinduced periinfarct ischemia by thallium scintigraphy was present in $50 \%$ of those with infarct vessel stenosis $\geq 50 \%$.

The high incidence of exercise-induced ischemia in this study may be related to enhanced myocardial salvage or greater sensitivity of tomographic thallium scintigraphy. Only one of seven patients with periinfarct ischemia by thallium developed ischemic ECG changes with exercise. It is known that stress ECG is not a sensitive measure of ischemia in the setting of baseline ST segment changes or $Q$ waves. ${ }^{12}$ The sensitivity of thallium imaging after infarction is greater than stress ECG alone and a positive result has been shown to have poor prognostic implications. ${ }^{13}$

All deaths occurred in patients with high-grade residual stenosis; three of these four patients had unsuccessful reperfusion. Other investigators have also found a higher mortality rate in patients with an occluded infarct vessel. ${ }^{14-16}$ Although the numbers are small, the lack of mortality among patients with a widely patent infarct vessel after t-PA and angioplasty is noteworthy.

Spontaneous or provocable ischemia prompted delayed in-hospital revascularization with PTCA or bypass grafting in $53 \%$ of survivors with high-grade infarct vessel stenosis. This finding underscores the importance of a high-grade lesion of the infarct vessel for instability.

Predictors of reocclusion. Coronary arterial reocclusion remains a significant problem after successful thrombolytic therapy. Recent studies have shown that after successful thrombolysis by means of 90- to 180-minute infusions of t-PA, early reocclusion occurs in $33 \%$ to $45 \%$ of infarct arteries. ${ }^{17,18}$ With prolonged (6- to 8-hour) infusions of t-PA in a larger trial of 386 patients, the combined incidence of reocclusion and recurrent ischemic events was less than $20 \% .^{19}$ In the present study, the relatively high incidence of reocclusion and recurrent ischemic events probably relates to the lower total dose of t-PA and the shorter duration of infusion used.

Suboptimal (TIMI 2) flow was associated with a higher rate of reocclusion, which may have resulted from the increased likelihood of rethrombosis in a diminished flow state. An interesting finding was that of intermittent patency of the infarct artery observed between the 60-,90-, and 120-minute angiograms. This finding was observed in five arteries, two which failed reperfusion despite t-PA and PTCA, and the remaining three vessels reoccluded. Therefore, intermittent patency during infusion of
t-PA resulted in a totally occluded infarct artery in each instance. Fluctuations in coronary flow after experimental thrombosis and reflow have been previously documented. ${ }^{20}$ This finding may represent platelet-mediated vasoconstriction or enhanced thrombotic tendency.

One half of all reocclusions were associated with chest pain and ECG changes prompting emergency recatheterization. Four of five "silent" reocclusions occurred in patients with well-developed collateral arteries completely filling the infarct artery at the time of follow-up catheterization. One of these patients showed periinfarct redistribution on exercise thallium scintigraphy. This data would suggest that "silent" reocclusions are not always the result of lack of viable myocardium perfused by the infarct vessel. The development of collateral arteries may have protected these patients from reinfarction or perhaps denervation of the infarct area prevents clinically recognized angina. Silent ischemia may, in fact, be more common after acute $\mathrm{MI}_{.}^{21,22}$

Limitations. The results are from a relatively small population of patients who underwent acute intervention; thus, they must be interpreted with caution. A patient with total occlusion of the infarct artery may have a particularly poor prognosis compared to a patient with partial reperfusion. ${ }^{23}$ Thus, inclusion of patients with total $(100 \%)$ occlusion in the group with $\geq 50 \%$ residual stenosis in our study may represent a particularly skewed group with respect to negative clinical outcome. However, only 4 of 50 patients had unsuccessful reperfusion. Three of the four deaths occurred in patients with $100 \%$ occlusion. The remaining patient with unsuccessful reperfusion had no in-hospital cardiac complications.

The need for delayed revascularization was determined by recurrent ischemic events. However, despite documented ischemia in three patients with $<50 \%$ residual stenosis, revascularization was only performed in one. In many cases the requirement for delayed PTCA or bypass surgery may have been the presence of high-grade stenosis.

Implications. These data identify patients at high risk for reocclusion of the infarct artery after t-PA infusion, PTCA, or both. Patients with suboptimal (TIMI 2) flow or intermittent patency during infusion of t-PA had the highest rate of reocclusion. The inability to achieve sustained arterial patency despite the use of t-PA and PTCA suggests that other measures, including coronary bypass surgery, nonselective thrombolytic agents, or coronary stents, need to be evaluated in patients at high risk of reocclusion. After therapy with t-PA or angioplas- 
ty, a vessel with residual stenosis of $\geq 50 \%$ is associated with an increased risk of death, recurrent ischemic events, and the need for subsequent revascularization. This suggests that PTCA, if performed, should ideally reduce the stenosis of the infarct artery to $<50 \%$.

We thank Eva Kline-Rogers, R.N., and Laura Gorman, R.N., for research nursing assistance and Mrs. Betty Plunkett for manuscript preparation.

\section{REFERENCES}

1. Gruppo Italiano Per Lo Studio Della Streptochinasi Ne 'Infarto Miocardio (GISSI). Effectiveness of intravenous thrombolytic treatment in acute myocardial infarction. Lancet 1986;1:397.

2. Simoons ML, Brand M V/D, de Swaan C, et al. Improved survival after early thrombolysis in acute myocardial infarction. Lancet 1985;2:578.

3. European Cooperative Study Group. Streptokinase in acute myocardial infarction. N Engl J Med 1979;301:797.

4. ISIS Steering Committee. Intravenous streptokinase given within 0-4 hours of onset of myocardial infarction reduced mortality in ISIS-2. Lancet 1987;1:502.

5. The ISAM Study Group. A prospective trial of intravenous streptokinase in acute myocardial infarction (ISAM). N Engl J Med 1986;314:1465.

6. Kennedy JW, Stewart DK. Interventional coronary arteriography. Annu Rev Med 1984;35:513.

7. O'Neill $W$, Timmis $G$, Bourdillon $P$, et al. A prospective randomized clinical trial of intracoronary streptokinase versus coronary angioplasty therapy of acute myocardial infarction. N Engl J Med 1986;314:812.

8. Fung AY, Lai $P$, Juni JE, et al. Prevention of subsequent exercise-induced periinfarct ischemia by emergency coronary angioplasty in acute myocardial infarction: comparison with intracoronary streptokinase. J Am Coll Cardiol 1986;8:496.

9. Topol EJ, O'Neill WW, Langburd AB, et al. A randomized, placebo-controlled trial of intravenous recombinant tissuetype plasminogen activator and emergency coronary angioplasty in patients with acute myocardial infarction. Circulation 1987;75:420.

10. The TIMI Study Group. The thrombolysis in myocardial infarction (TIMI) trial. N Engl J Med 1985;3:2:932.

11. LeFree MT, Simon SB, Mancini GBJ, Vogel RA. Digital radiographic assessment of coronary arterial geometric diameter and videodensitometric cross-sectional area. Soc Photo Optical Instrumentation Eng Med 1986;626:36i4.
12. Ahnve SA, Savvides M, Abouantoun S, Atwood JE, Froelicher V. Can myocardial ischemia be recognized by the exercise electrocardiogram in coronary disease patients with abnormal resting Q waves? AM HEART J 1986;111:909.

13. Gibson RS, Watson DD, Craddock GB, et al. Prediction of cardiac events after uncomplicated myocardial infarction: a prospective study comparing predischarge exercise thallium201 scintigraphy and coronary angiography. Circulation 1983; 68:321.

14. Lew A., Geft I, Rodriquez L, Shah PK, Swan HJC, Ganz W. Short- and long-term mortality following intracoronary or intravenous streptokinase in acute myocardial infarction. $J$ Am Coll Cardiol 1985;5:496.

15. Califf RM, Kereiakes DJ, George BS, et al. Failure to reperfuse with tissue plasminogen activator predicts high reocclusion rate after angioplasty. Circulation 1986;74(suppl II):II-25.

16. Dodge HT, Sheehan FH, Mathey DG, Brown BG, Kennedy $\mathrm{JW}$. Usefulness of coronary artery bypass graft surgery or percutaneous transluminal angioplasty after thrombolytic therapy. Circulation 1985;72:V39.

17. Williams $D O$, Borer $\mathrm{J}$, Braunwald $\mathrm{E}_{\text {, et al. Intraveneous }}$ recombinant tissue-type plasminogen activator in patients with acute myocardial infarction: a report from the NHLBI thrombolysis in myocardial infarction trial. Circulation 1986; 73:338.

18. Gold HK, Leinbach RC, Garabedian HD, et al. Acute coronary reocclusion after thrombolysis with recombinant human tissue-type plasminogen activator: prevention by a maintenance infusion. Circulation 1986;73:347.

19. Topol EJ, Culif RM, George BS, et al, and the TAMI Study Group. A randomized trial of immediate versus delayed elective angioplasty after intravenous tissue plasminogen activator in acute myocardial infarction. N Engl J Med 1987;317:581.

20. Schumacher WA, Buda AJ, Lucchesi BR. Streptokinase thrombolysis in experimental coronary artery thrombosis: pattern of reflow and effect of a stenosis. Int J Cardiol 1984; 6:615.

21. Bigger T, Moss A, and the Multicenter Diltiazem Post Infarction Trial Investigators. Silent ischemia after myocardial infarction. J Am Coll Cardiol 1987;9:68A.

22. Gibson RS, Beller GA, Kaiser DL. Prevalence and clinical significance of painless ST segment depression during early postinfarction exercise testing. Circulation 1987;75:II-36.

23. Stadius ML, Davis K, Maynard C, Richie JL, Kennedy JW. Risk stratification for 1 year survival based on characteristics identified in the early hours os acute myocardial infarction. The Western Washington Intracoronary Streptokinase Trial. Circulation 1986;74:708.

\section{FDA GRANTS AVAILABLE}

The Food and Drug Administration's (FDA) Office of Orphan Products Development (OPD) is soliciting applications for grants for clinical trials of products that are useful in treating a rare disease or condition. These products include drugs, biologics, medical devices, and foods for medical purposes. For information contact: Ms. Carol Wetmore, FDA/OPD/HF-35, 5600 Fishers Lane, Rockville, MD 20857, phone 301-44:3-4903. 